IRA-International Journal of Technology \& Engineering ISSN 2455-4480; Vol.05, Issue 01 (2016)

Pg. no. 12-17

Institute of Research Advances

http://research-advances.org/index.php/IRAJTE

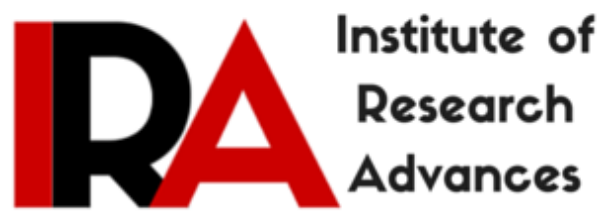

\title{
Digital Wallet System for Smart Ticketing
}

\section{Vinay Kumar Reddy Kaitha ${ }^{1}$, Bala Naga Vamsidhar Grandhi ${ }^{2}$, Vinay Babu Kosaraju $^{3}$}

${ }^{1,3}$ Master of Science-Computer \& Systems Engineering

${ }^{2}$ Master of Science-Electrical \& Electronics Engineering

1,2,3, University of Houston Houston, Texas, USA.

Type of Reviewed: Peer Reviewed.

DOI: http://dx.doi.org/10.21013/jte.v5.n1.p3

\section{How to cite this paper:}

Kaitha, V., Grandhi, B., \& Kosaraju, V. (2016). Digital Wallet System for Smart Ticketing. IRA-International Journal of Technology \& Engineering (ISSN 2455-4480), 5(1), 12-17. doi:http://dx.doi.org/10.21013/jte.v5.n1.p3

(C) Institute of Research Advances

(c) EY-NC

This work is licensed under a Creative Commons Attribution-Non Commercial 4.0 International License subject to proper citation to the publication source of the work.

Disclaimer: The scholarly papers as reviewed and published by the Institute of Research Advances (IRA) are the views and opinions of their respective authors and are not the views or opinions of the IRA. The IRA disclaims of any harm or loss caused due to the published content to any party. 


\section{ABSTRACT}

This paper briefly discusses an effective, efficient, convenient ticketing system designed especially for the transportation system in the Indian Subcontinent, which can be also extended to different types of domain by introducing few changes in design according to working environment. This system reduces man power which in turn reduces the maintenance costs to a greater extent.

Keywords - Smart Cards, Smart Card Reader, AVR microcontroller, ATMEGA16, LCD, Clock circuit, Security, Efficient

\section{INTRODUCTION}

In the Indian Subcontinent, money plays a crucial and major medium for the exchange of goods. This project tries to design an effective medium (Smart Card Technology) that replaces the money. The ticket collector may not have sufficient money to provide the change to the all passengers, which creates a bad impression about the public transportation. Sometimes the passengers forget to collect their money as there are in a hurry to get down the bus. We often see people who lose their wallets and they don't have any knowledge about it, in such cases we are not able to retain their lost money. These kind of issues can be easily addressed if we design a system that can effectively replace the current monetary medium with a high level security. In simple words this system should be able to defend itself from the unauthorized users. One such kind of system is Smart Card Technology. A smart card is an embedded device that facilitates identification, authorization, data storage and application processing. It is very light weight and easy to carry, has predefined information to prevent it from the unauthorized activity.

\section{PROPOSED ARCHITECTURE}

The design of the system is built using seven modules, of which ATmega16 microcontroller is the heart of the system.

1. Microcontroller (ATmega16)

2. Power Supply

3. Clock Circuit

4. Reset Circuit

5. LCD Supply

6. Card Reader

7. Smart Card

The microcontroller in our project is an 8 bit CMOS microcontroller which is based on AVR enhanced RISC architecture. By executing powerful instruction in one clock cycle ATmega16 achieves throughputs approaching 1 MIPS per $\mathrm{MHz}$ allowing system designer to optimize power consumption versus processing speed. The RISC architecture increases the execution speed of the instructions because of the reduced set of instructions. 


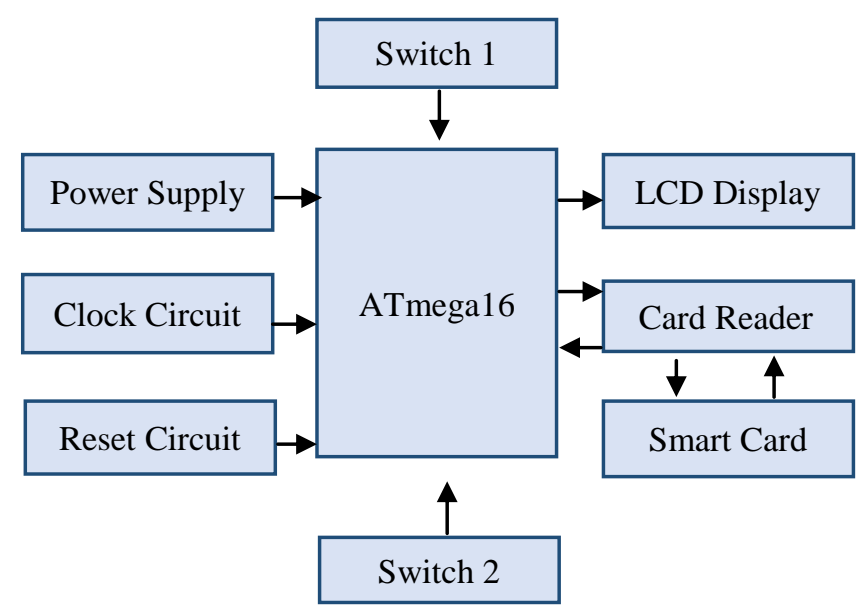

Figure 1. Block diagram of the proposed design

\section{WORKING}

The most crucial task in this system is to create a reliable communication between different modules of the system. When a passenger boards a bus equipped with kind of technology, he primarily needs a smart card (we can add the monetary transactions as the secondary method so that a passenger without a smart card is also able to board the bus). Once the passenger makes a contact against the card reader, it should be able to read the contents of the card, communicate the information with the microcontroller, process the balance deductions and show any errors messages (if any) with in a fraction of seconds. The LCD display is used to display any error messages and a reset circuit is powerful enough to restart the system within a few seconds.

\section{OPERATION}

The system gets into processing once the passenger taps the card against the smart card reader (we can make the interface between the card and card reader either as a contact one or a contact less one depending on the environment we are targeting at). The card will be having specific information about the authorization, identity and balance amount. The balance amount can be recharged regularly at the public transportation offices. To improve the security of the system we can add a 4 digit pin to prevent unauthorized access. Once the card reader reads the balance information, the passenger presses one of the switches (Switch 1 or Switch 2) depending on his destination address. If the destination is in 5kms range he will press one, if it is greater than $5 \mathrm{kms}$ then he will press Switch 2. Depending on the number of destinations we can vary the number of switches.

Later in the next step the microcontroller comes into play to decide whether there is enough balance amount in the card for the passenger to travel to his destination. If the balance is low then the passenger can reload the card in the backside of the bus which will have a card reloading device or he can also pay for his ride in cash. If there is enough balance in the card to take a ride then the microcontroller will deduct the fare from the balance available and write the new balance into the card. 
The project setup and real demonstration is shown below

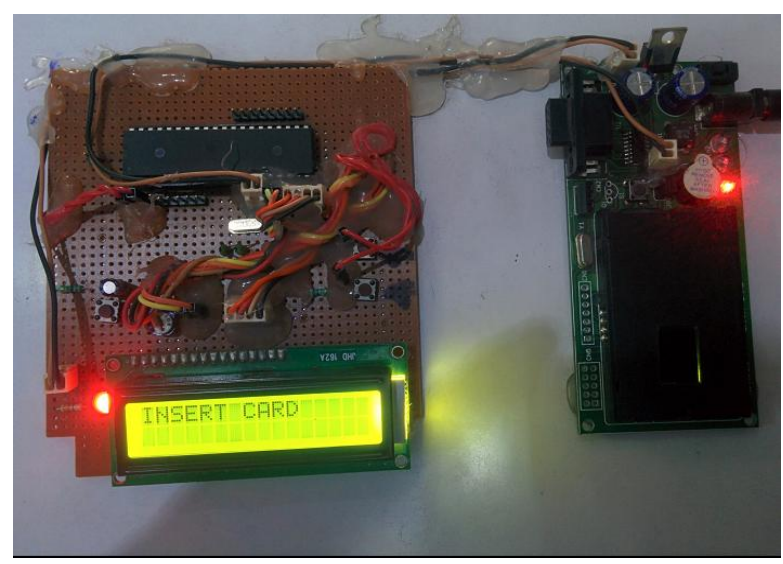

Figure 2.System asking to insert the card

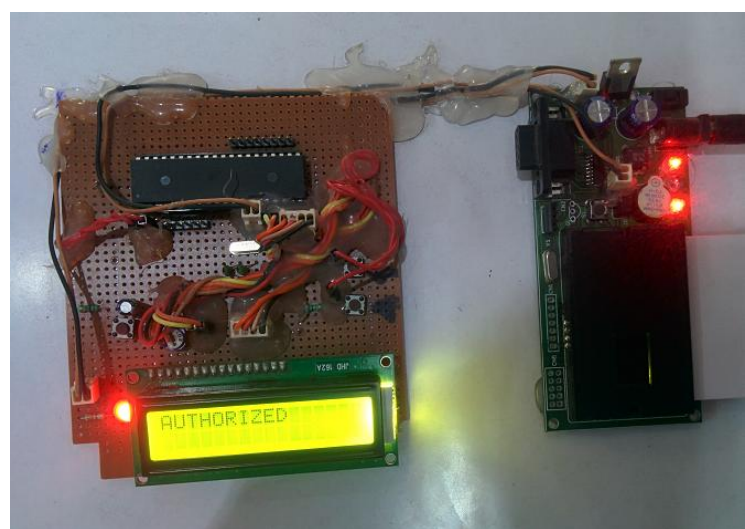

Figure 3. Card authorization is completed

Once the card is authorized, the LCD display shows the amount of current balance and also shows the remaining balance after deducting the fare from the smart card.

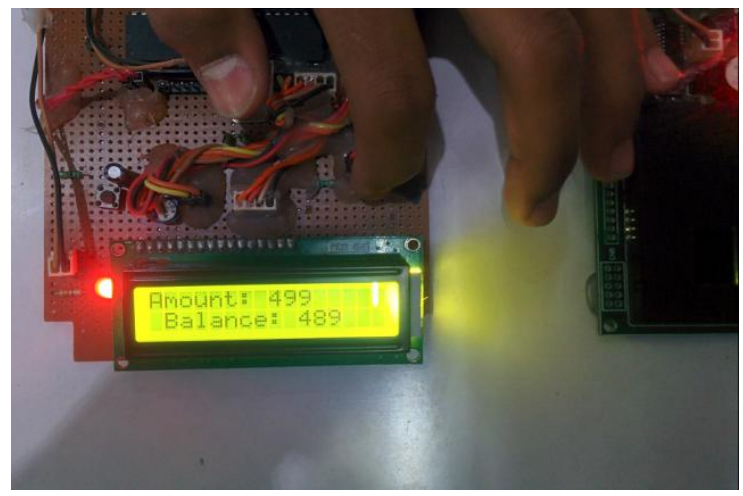

Figure 4. Available balance amount in the card and balance amount after deducting the fare amount. 


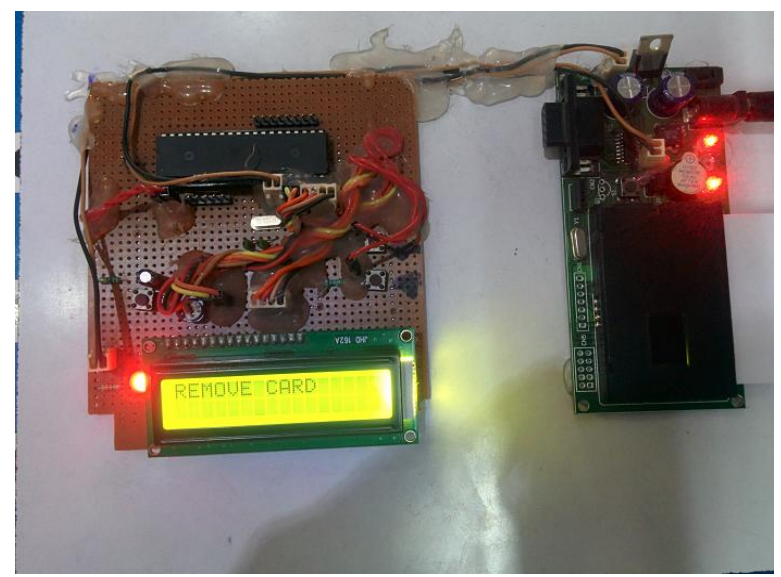

Figure 5. After the processing the card is removed.

\section{HARDWARE CONSIDERATIONS}

The power supply used for the controller circuits is $5 \mathrm{v}$ DC, the available 230v AC supply must be stepped down to produce the required dc. This stepped down AC voltage is given to IC7805 voltage regulator to maintain a stable voltage that is time invariant. A clock circuit is implemented so that all the interconnected modules in the circuit have a synchronous communication between each other.

When powering up any microcontroller, before the power supply reaches its final state it goes through many different voltage ranges, where the device is not guaranteed to operate in all such voltage ranges. Since some device cells may operate at a lower voltage levels than the others, the device may power up in an unknown state. To ensure that the device operates in a known state we need a reset circuit. This can be achieved by adding an external reset circuit to the system design.

As this design is a prototype for the real time scenario the instruction size of our design is small and the memory needed is also small, so we opted ATmega16 an 8bit microcontroller. The RS-232 communication standard is employed in employed in our design, which is serial communication standard for the transmission of the data. The LCD display in this circuit is of size 2 lines X 4characters, which requires only 11 pin connection of which 8 pins are for data and the remaining 3 pins for the control signals.

\section{SOFTWARE IMPLEMENTATION}

The software tools used for this project are Atmel Studio and ProgISP

The Atmel Studio is provided by the Atmel in order to help developers to create applications for AVR microcontroller using $\mathrm{C} / \mathrm{C}++$ programming languages

ProgISP is used to load the hexadecimal file into the target IC

\section{FUTURE SCOPE}

The scope of this prototype can be extended to wide domains other than the transportation system, like shopping mall or loyal customer reward cards. The customers who visit regularly to a particular shop can earn bonus points which can be later used for their future purchases. If the shop management cannot refund the money to the customers in cash, then they can load the same amount of money in the card and the customers can take benefit of it for their future needs. As the smart cards are really smart enough to authorize an identity, we can use them as the authorization pass to enter a restricted access zone. To 
enhance the performance of this system we can add multiple types of inputs to the system and we can efficiently mount a printer device that can print the bills apart from showing the balance in the LCD display.

\section{CONCLUSION}

We are living in an era that sees the change and development which once were considered to be unimaginable and impossible. Due to revolution, research and changing trends in the markets the world is completely transformed into a digital entity. The whole world can be at your fingertips with a single click. In order to survive and establish ourselves in this modern we must transform our thoughts and ideas continuously, we must be able to adapt to the changes, working environment and should try to be ahead by at least two steps.

Our Smart Ticketing System is a kind of effort from us to change the current medium of transactions, by providing high level of security at the same time. We are currently working on to take our design to the next level, which would tackle the issues in the real time which is capable of handling multiple users in a range of time. This next level design will be embedded with a small keypad, a printer module, contactless card readers so that the present system gets smarter, effective and reliable.

\section{REFERENCES}

[1]. "ISO/IEC 7816-2:1999/Amd 1:2004 - Assignment of contacts C4 and C8".www.iso.org. Retrieved 2015-08-20.

[2]. Multi-application Smart Cards. Cambridge University Press.

[3]. ISO/IEC 7816-3:2006 Identification cards - Integrated circuit cards — Part 3: Cards with contacts

- Electrical interface and transmission protocols, clause 8.2.3

[4]. "The AVR Microcontroller and C Compiler Co-Design"

[5]."AVR Hardware Design Considerations",Atmel Corporation. Jun 2015. p. 5. Retrieved 14 Jun 2015

[6]. Smart Research and Advanced Apllications by Gilles Grimaud, Fransisco-Xavier Standaert

[7]. Smart Card Handbook, $4^{\text {th }}$ edition by Wolfgang Rankl and Wolfgang Effing. 